\title{
Gain Enhancement of Circular Microstrip Patch Antenna Using Dual-FSS Superstrate Layer for ISM Band
}

\author{
Shitiz Upreti ${ }^{1}$, Saurabh Katiyar ${ }^{2}$ \\ ${ }^{1,2}$ (Department of Electronics \& Communication, G.C.E.T Engineering College, Greater Noida, U.P, India)
}

\begin{abstract}
In this paper, an effort is made to optimize the gain to show better performance analysis on the basis of design and simulation results by implementing FSS structured superstrate layer with circular microstrip patch antenna at operating frequency of $5.8 \mathrm{GHz}$ for ISM Band applications. In this proposed antenna, co-axial feeding technique is utilized in order to have better impedance matching effects. In order to show our results better, we have made a comparative analysis with conventional microstrip patch antenna at the same frequency band to increase the gain, directivity and minimize the return loss of the desired antenna. In addition to this, it shows the advantages of utilizing the ism band and fss superstrate layers compared to other frequency bands. Full wave 3-D simulation results is carried out by using Ansoft based HFSS software, that is, based on Finite Element Method (FEM) modeling technique.
\end{abstract}

Keywords:Microstrip Antenna, FSS, ISM Band, Co-axial Feed, Impedance Matching. Directivity, Return Loss.

\section{Inroduction}

In the field of RF communication, Frequency Selective Surface (FSS) plays an important role in enhancement of gain that are periodic surfaces combination of identical elements in one or two-dimensional construction designed as a electromagnetic filter in order to avoid interference of transmission and reception of signals in the microstrip antennas. Two basic characteristics of FSS are Narrow Bandwidth and Periodicity in two dimensions [1]. FSS has become an alternative to the fixed frequency meta-material; where static geometries and spacing of unit cells determine the frequency response of a given met material. FSS was first developed to control the transmission and reflection characteristics of an incident radiation wave. This has resulted in smaller cell size along with increases in bandwidth and the capability to shift frequencies in real time for artificial materials. In this paper, we proposed a dual FSS Superstrate Layer with circular microstrip patch antenna at operating frequency of $5.8 \mathrm{GHz}$ for ISM Band applications which provides the enhancement of gain and minimization of return loss . The main purpose of using fss on superstrate layer is to provide protective shield for microstrip patch antenna to reduce insertion losses and also, acts as a conducting patches to transmit better radiating signals in order to achieve desired antenna's efficiency. In addition, the use of FSS superstrate layer makes the antenna much easier to fabricate via the use of etching processes.

\section{Antenna Design Analysis}

Microstrip antenna is also called printed circuit antenna or patch antenna. When conformal and low profile antennas are requested, the microstrip antenna is the best choice. This type of antenna also has the advantage of low cost and weight, reproducibility, design flexibility and ease of installation [10]. The modes supported by the circular patch antenna can be found by treating the patch, ground plane, and the material between the two as a circular cavity.

The procedure assumes that the specified information includes the dielectric constant of the substrate $\left(\varepsilon_{\mathrm{r}}\right)$, the resonant frequency $\left(\mathrm{f}_{\mathrm{r}}\right)$ and the height of the substrate $\mathrm{h}$. The procedure is as follows:

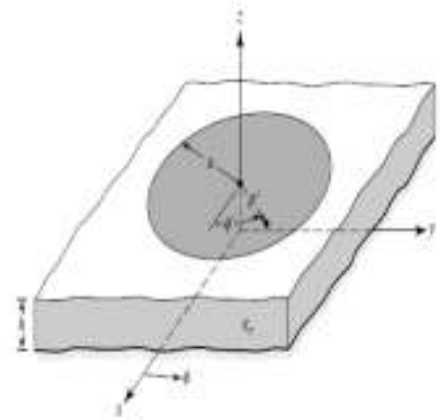

Figure 2.1: Geometry of Circular Patch Antenna. 


\subsection{Actual Radius and Effective Radius of Circular Patch Antenna:}

Since the Dimensions of the patch are in the circular form, the actual radius of the circular patch antenna is given by:

$\mathrm{a}=\frac{\mathrm{F}}{\left\{1+\frac{2 \mathrm{~h}}{\left.\Pi \frac{{ }_{\mathrm{r}} \mathrm{F}}{2 \mathrm{~h}}(\underline{\ln (\Pi)}+1.7726]\right\}^{\wedge} 1 / 2}\right.}$

Where

$$
\mathrm{F}=\frac{8.791 \times 10^{\wedge 9}}{\mathrm{f}_{\mathrm{r}}(\square \mathrm{r})^{\wedge} 1 / 2}
$$

Eqn.1 does not take into account the fringing effects.. But for the rectangular patch, fringing makes the patch look electrically larger and it was taken into account by introducing a length correction factor. Similarly for the circular patch a correction is introduced by using an effective radius $a_{e}$, to replace the actual radius $a$ :

$$
\mathrm{a}_{\mathrm{e}}=\mathrm{a} *\left\{1+\underset{\Pi \square_{\mathrm{r}}}{2 \mathrm{~h} *[\ln (\Pi \mathrm{a})+1.7726]\}^{\wedge} 1 / 2}\right.
$$

2.2 Resonant Frequency:

The Resonant Frequency for the dominant mode $T M_{110}^{z}$ should be modified by using effective radius $a_{e}$ and expressed [9] as:

$$
f_{r}=\frac{1.841 c}{2 \pi a_{e} \sqrt{\varepsilon_{r}}}
$$

\section{Antenna Design Specifications}

The Proposed Circular Microstrip Patch Antenna (CMPA) by integrating Dual FSS Superstrate Layer at operating frequency of $5.8 \mathrm{GHz}$ was designed by using the following specifications:

Table-3.1: Design Specifications of Circular Microstrip Patch Antenna with Dual FSS Superstrate Layer.

\begin{tabular}{|l|l|}
\hline PARAMETERS & VALUES \\
\hline Frequency Band Used: & ISM Band \\
\hline Operating Frequency(fo): & $5.8 \mathrm{GHz}$ \\
\hline Substrate Material used: & RT-Duroid $5880 \mathrm{tm}$ \\
\hline Substrate Dielectric Material: & 2.2 \\
\hline Substrate Thickness: & $0.762 \mathrm{~mm}$ \\
\hline Radius of Circular Patch: & $9.88 \mathrm{~mm}$ \\
\hline Feeding Technique Used: & Probe Feeding Technique \\
\hline FSS Layer above Superstrate: & FR-4 epoxy \\
\hline FSS Layer below Superstrate: & RT-Duroid 5880 tm \\
\hline FSS Radius above Superstrate Layer: & R $=2.5 \mathrm{~mm}$ \\
\hline FSS Radius below Superstrate Layer: & $\mathrm{R}=2.0 \mathrm{~mm}$ \\
\hline Feed Point Location from Centre: & $3.1 \mathrm{~mm}$ from Centre \\
\hline $\begin{array}{l}\text { Air-Gap Height b/w Substrate \& } \\
\text { Superstrate }\end{array}$ & $28.96 \mathrm{~mm}$ \\
\hline
\end{tabular}

\section{Antenna Proposed Structure}

In this Proposed Structure, we have employed a Circular Microstrip Patch Antenna (CMPA) with and without using Dual FSS Superstrate Layer at Resonant Frequency of $5.8 \mathrm{GHz}$ (for ISM Band).In order to design, simulate and analyze this structure properly by using the above design specifications, we have implemented Ansoft Based HFSS version 12.0 Software. The Basic Features related to HFSS Software:

1. HFSS stands for High Frequency Structure Simulator and is a commercial finite element method solver for electromagnetic structures. 
2. It is one of several commercial tools used for antenna design, and the design of complex RF electronic circuit elements including filters.

3. It was originally developed by Professor Zoltan Cendes and his students at Carnegie Mellon University. Prof.Cendes and his brother Nicholas

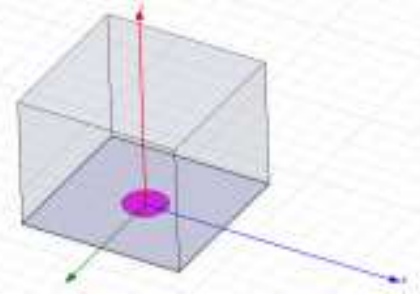

Figure-4.1: Conventional Circular MicroStrip Patch Antenna HFSS in HFSS Software

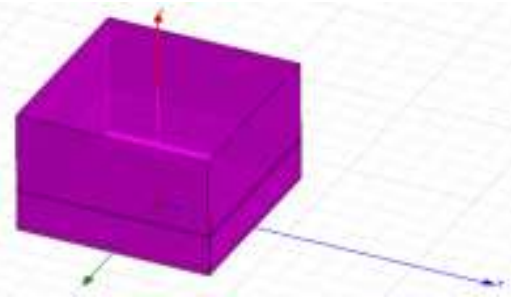

Figure-4.2: Proposed Antenna Structure in Software.

\section{Simulation Results \& Discussion}

5.1 Simulation Results of Normal Circular MicroStrip Patch Antenna without Dual FSS Layer: 5.1.1Return Loss:

1.Operating Frequency: $5.8 \mathrm{GHz}$

2.Value of Return Loss (in db): $-13.7496 \mathrm{db}$

3.Peak Point (m1) of Operating Frequency: $5.7889 \mathrm{GHz}$

\subsubsection{Gain Total:}

1.Operating Frequency: $5.8 \mathrm{GHz}$

2.Value of Gain Total (in db): $7.1479 \mathrm{db}$

3.Peak Point (m1) of Operating Frequency: $5.7789 \mathrm{GHz}$

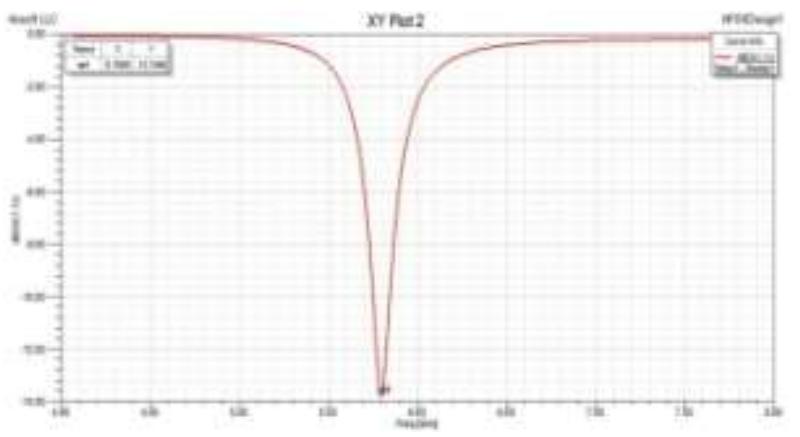

Figure-5.1.1: Return Loss (in db) without Dual FSS FSS

\subsubsection{Radiation Pattern:}

1. Operating Frequency: $5.8 \mathrm{GHz}$

2. Setup1: Sweep1

3. Peak Point (m1) of Operating Frequency: $5.77899 \mathrm{GHz}$

4. $\mathrm{Phi}$ (in degree) $=0$ degree; $\mathrm{Phi}$ (in degree) $=90$ degree

\subsubsection{Directivity:}

1. Operating Frequency: $5.8 \mathrm{GHz}$

2. Setup1: Sweep1

3. Peak Point (m1) of Operating Frequency:

4. Phi (in degree $)=0$ degree $;$ Phi (in degree $)=90$ Degree

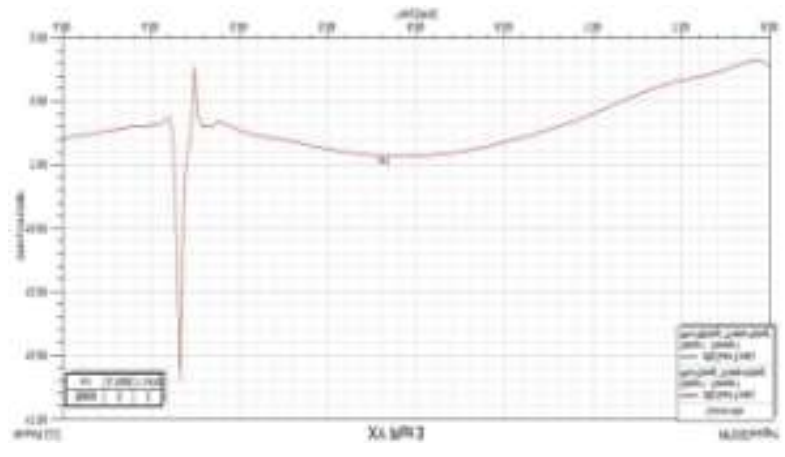

Figure-5.1.2: Gain Total (in db) without Dual 


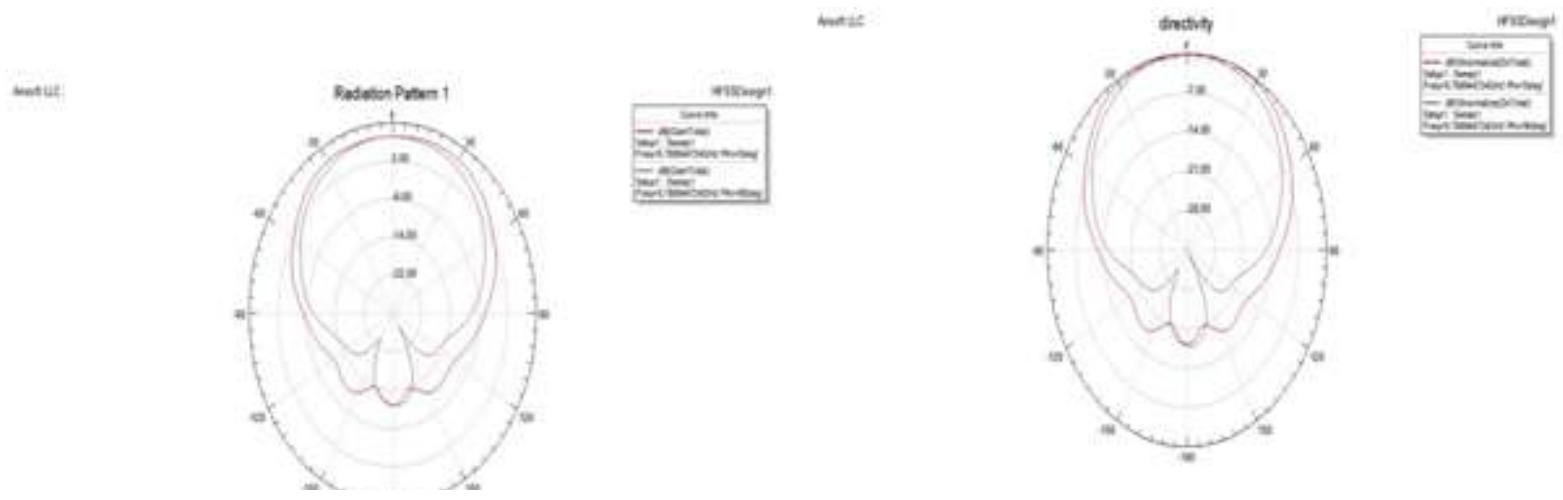

Figure 5.1.3: Radiation Pattern without Dual FSS

Figure 5.1.4: Directivity without Dual FSS

5.2 Simulation Results of Circular MicroStrip Patch Antenna with Dual FSS Layer:

\subsubsection{Return Loss:}

1. Operating Frequency: $5.8 \mathrm{GHz}$

2. Value of Return Loss (in $\mathrm{db}):-19.5858 \mathrm{db}$

3. Peak Point (m1) of Operating Frequency: $5.7889 \mathrm{GHz}$

\subsubsection{Gain Total:}

1. .Operating Frequency: $5.8 \mathrm{GHz}$

2. Value of Gain Total (in db): $10.9146 \mathrm{db}$

3. Peak Point (m1) of Operating Frequency: $5.8090 \mathrm{GHz}$

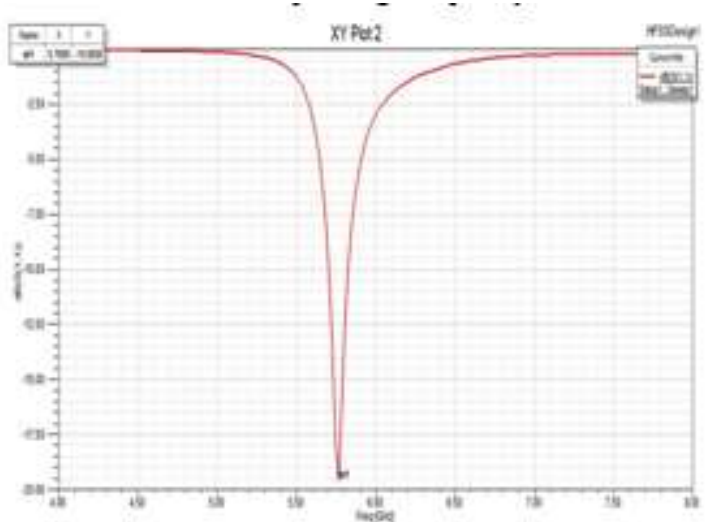

Figure 5.2.1 Return Loss (in db) with Dual FSS

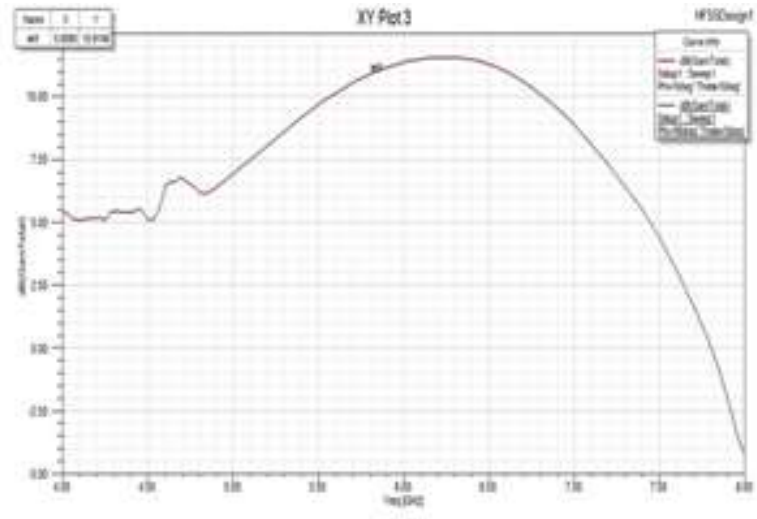

Figure 5.2.2 Gain Total (in db) with Dual FSS

\subsubsection{Radiation Pattern:}

1. Operating Frequency: $5.8 \mathrm{GHz}$

2. Setup1: Sweep1

3. Peak Point (m1) of Operating Frequency: $5.8020 \mathrm{GHz}$

4. Phi (in degree) $=0$ degree; Phi (in degree $)=90$ degree

\subsubsection{Directivity:}

1 .Operating Frequency: $5.8 \mathrm{GHz}$

2. Setup1: Sweep1

3. Peak Point (m1) of Operating Frequency: $5.77899 \mathrm{GHz}$

4. Phi (in degree) $=0$ degree; Phi (in degree) $=90$ degree 


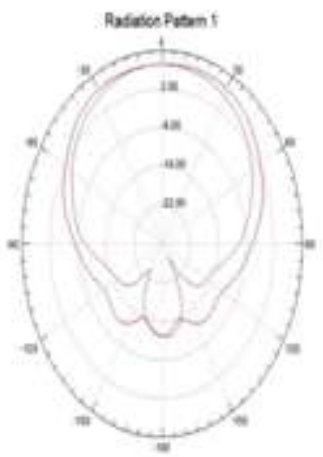

Figure 5.2.3: Radiation Pattern with Dual FSS
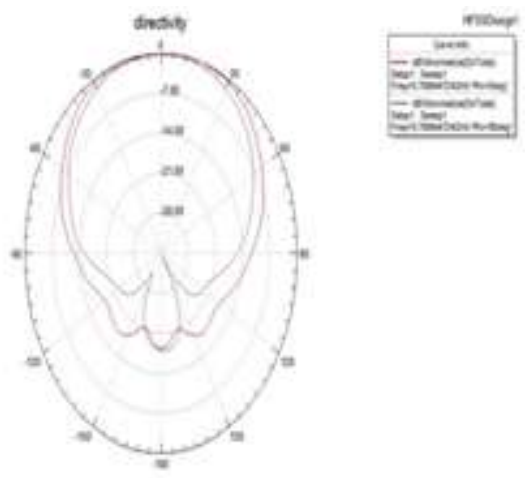

Figure 5.2.4: Directivity with Dual FSS

\section{Conclusion}

In this paper, design and simulation of dual fss superstrate layer composed with circular patch antenna provides better performance analysis through enhancement of gain, directivity and minimization of return loss. In this proposed antenna, circular slots of fss layer with lower radius size (in $\mathrm{mm}$ ) worked as better radiation and minimum reflection of signals which increases antenna's efficiency. Secondly, it acts as a protective shield (i.e. dielectric radomes) against various insertion losses for circular microstrip patch antenna. To this proposed antenna system, about $52.7 \%$ increment in gain and around $42.47 \%$ minimization of return loss is achieved. Simulation results are carried out by using Ansoft based HFSS version 12.0 software.

\section{Acknowledgement}

The Authors express their appreciation to Dr. R.L Yadava, Professor and Mr. Deepak Gangawar, Asst.Professor, Department of Electronics and Communication, Engineering, Galgotia's College of Engg. \& Technology (G.C.E.T), Greater Noida (U.P) for their technical support and valuable advices.

\section{Journal Papers}

\section{References}

[1] Abbas Pirhadi, Hadi Bahrami, and Javad Nasri, Wideband High Directive Aperture Coupled Microstrip Antenna Design by Using a FSS Superstrate Layer, IEEE Trans. Antennas Propag. Vol. 60, No.4, April 2012.

[2] A. Foroozesh and L. Shafai, Investigation Into the Effects of the Patch-Type FSS Superstrate on the High-Gain Cavity Resonance, IEEE Trans. Antennas Propag., Vol. 58, No.2, February2010.

[3] Muhammad Mahfuzul Alam, Md. Mustafizur Rahman Sonchoy, and Md. Osman Goni, "Design and Performance Analysis of Microstrip Array Antenna”, Progress In Electromagnetic Research Symposium Proceedings, Moscow, Russia, August 18 -21, 2009.

[4] Gonca, C. Design, Simulation and Tests of Low-cost Microstrip Patch Antenna Arrays for the Wireless Communication Turk J Elect Engin, 13 (1), 2005.

[5] Asghar Keshtkar, Ahmed Keshtkar and A. R. Dastkhosh, Circular Microstrip Patch Array Antenna for C-Band Altimeter System,International Journal of Antenna and Propagation, article ID 389418, doi:10.1155/2008/389418, November, 2007.

[6] M. F. Islam, M. A. Mohd. Ali, B. Y. Majlis and N. Misran, Dual Band Microstrip Patch Antenna for Sar Applications, Australian Journal of Basic and Applied Sciences, 4(10): 4585- 4591, 2010.

[7] L. Leger, T.Monediere, and B. Jecko, Enhancement of gain and radiation bandwidth for a planar 1-D EBG antenna, IEEE Microw. Wireless Compon. Lett. vol. 15, no. 9, pp. 573-575, 2005

[8] Yadav, R. K \& Yadava, R.L, "Superstrate Loaded Rectangular Microstrip Antennas -An Overview International journal of Information, Intelligence and Knowledge (JIIK) Volume 3, Issue, 2011.

[9] T. F. Lai, Wan Nor Liza Mahadi, Norhayatision, Circular Patch Microstrip Array Antenna for KU-band, World Academy of Science, Engineering and Technology, vol. 48, pp. 298-302, 2008

Books

[10] Balanis C.A (1982) Handbook of Microstrip Antennas. John Wiley and Sons New York.

[11] Burkholder, R and Lundin, T. (2006). Antenna and Radiation Pattern. IEEE. Transactions on Antennas and Propagation, 53(2):

[12] Gonca, C. (2005) Design, Simulation and Tests of Low-cost Microstrip Patch Antenna Arrays for the Wireless Communication Turk J Elect Engin, 13 (1)

[13] Richards, W.F. (1988) Microstrip Antennas. Theory, Application and Design. Van Reinhold Co., New York. 